\title{
Application of hot-film anemometry to resolve the unsteady boundary layer transition of a laminar airfoil experiencing limit cycle oscillations
}

\author{
Marc Braune $^{1} \cdot$ Stefan Koch ${ }^{2}$
}

Received: 17 October 2019 / Revised: 6 January 2020 / Accepted: 29 January 2020 / Published online: 13 February 2020

(c) The Author(s) 2020

\begin{abstract}
The unsteady boundary layer behavior of a supercritical laminar airfoil model, which undergoes limit cycle oscillations in pitch, is investigated by the application of hot-film anemometry. The data basis is a 2D flutter experiment under transonic flow conditions. The laminar airfoil model was elastically mounted with a single degree of freedom in pitch and performed self-excited limit cycle oscillations at a Mach number of $\mathrm{Ma}=0.73$ and a Reynolds number of $\mathrm{Re} \approx 2 \times 10^{6}$. An analysis of the hot-film signals on the basis of the quasi-wall shear stress is carried out, with which the boundary layer state for steady and unsteady flow is resolved. An algorithm is presented which allows an automated detection of the transition position, so that a correlation between airfoil motion and transition location movement can be quantified. A sudden movement of the boundary layer transition is observed at the upper and lower reversal points of the limit cycle oscillation, while in parts of the up- and downstroke of the laminar airfoil a shock-induced transition occurs. During the limit cycle oscillation, a delayed response of the boundary layer occurs, resulting in a significant phase lag between the movement of the boundary layer transition and the motion of the laminar airfoil.
\end{abstract}

\begin{tabular}{|c|c|c|c|}
\hline \multicolumn{2}{|c|}{ List of symbols } & \multirow{2}{*}{$\begin{array}{l}\mathrm{Ma} \\
p_{0}\end{array}$} & \multirow{2}{*}{$\begin{array}{l}\text { Mach number } \\
\text { Total pressure }(\mathrm{kPa})\end{array}$} \\
\hline$A$ & Constant & & \\
\hline$a$ & Overheat ratio & $\dot{Q}_{\mathrm{F}}$ & Heat transfer from hot-film sensor to flow (W) \\
\hline$\alpha$ & Mean angle of attack $\left({ }^{\circ}\right)$ & $\dot{Q}_{\mathrm{S}}$ & Heat transfer from hot-film sensor to substrate \\
\hline$\Delta \alpha$ & Pitch amplitude, pitch motion $\left({ }^{\circ}\right)$ & & $(\mathrm{W})$ \\
\hline$B$ & Constant & $\operatorname{Re}$ & Reynolds number \\
\hline$c$ & Chord length $(\mathrm{m})$ & $R_{0}$ & Nominal resistance $(\Omega)$ \\
\hline$c_{\mathrm{d}}$ & Drag coefficient & $R_{\mathrm{S}}$ & Operating resistance $(\Omega)$ \\
\hline$c_{1}$ & Lift coefficient & $s$ & Span $(\mathrm{m})$ \\
\hline$c_{\mathrm{m}}$ & Pitching moment coefficient & $\sigma$ & Standard deviation \\
\hline$c_{\mathrm{p}}$ & Pressure coefficient & $t$ & Time $(\mathrm{s})$ \\
\hline$c_{\mathrm{p}}^{*}$ & Critical pressure coefficient & $T_{0}$ & Reference temperature $(\mathrm{K})$ \\
\hline$D_{a}$ & Pitch damping coefficient (\%) & $T_{\mathrm{a}}$ & Ambient temperature $(\mathrm{K})$ \\
\hline$\delta$ & Boundary layer thickness & $T_{\mathrm{S}}^{a}$ & Operating temperature $(\mathrm{K})$ \\
\hline$f_{\alpha}$ & Pitch oscillation frequency $(\mathrm{Hz})$ & $T_{\Delta \alpha}$ & Period time (s) \\
\hline$I_{\alpha}$ & Mass moment of inertia (related to $c / 4)\left(\mathrm{m} \times \mathrm{s}^{2}\right)$ & $\Delta T$ & Temperature difference $(\mathrm{K})$ \\
\hline & & $\tau_{\mathrm{w}}$ & Real wall shear stress $\left(\mathrm{N} / \mathrm{m}^{2}\right)$ \\
\hline$\Delta$ & Marc Braune & $\tau_{\mathrm{q}}$ & Quasi-wall shear stress \\
\hline & marc.braune@dlr.de & $\tau_{\mathrm{q}, 1}$ & Empirical threshold \\
\hline & Stefan Koch & $u_{\infty}$ & Velocity of the inflow $(\mathrm{m} / \mathrm{s})$ \\
\hline & $\begin{array}{l}\text { Jteran Koch } \\
\text { stefan.koch@dlr.de }\end{array}$ & $U_{0}$ & Bridge zero voltage (V) \\
\hline & & $U$ & Bridge voltage $(\mathrm{V})$ \\
\hline 1 & DLR German Aerospace Center, Institute of Aeroelasticity, & $\varphi, \phi$ & Phase angle $\left({ }^{\circ}\right)$ \\
\hline & Bunsenstr. 10, 37073 Göttingen, Germany & $x$ & $x$-Coordinate $(\mathrm{m})$ \\
\hline & DLR German Aerospace Center, Institute of Aerodynamics & $x_{\text {tr }}$ & Position of boundary layer transition (m) \\
\hline & and Flow Technology, Bunsenstr. 10, 37073 Göttingen, & $y$ & $y$-Coordinate $(\mathrm{m})$ \\
\hline
\end{tabular}




$\begin{array}{ll}z & z \text {-Coordinate }(\mathrm{m}) \\ \omega^{*} & \text { Reduced frequency } \\ \text { CTA } & \text { Constant temperature anemometer } \\ \text { DNW } & \text { German-Dutch wind tunnels } \\ \text { TWG } & \text { Transonic Wind Tunnel Goettingen } \\ \text { DoF } & \text { Degree of freedom } \\ \text { LCO } & \text { Limit cycle oscillation } \\ \text { MHFS } & \text { Multiple hot-film sensor } \\ \text { RMS } & \text { Root-mean-square }\end{array}$

\section{Introduction}

Laminar flow technology is an ongoing object of research, as there is high potential of laminar airfoils to sufficiently reduce the fuel consumption and thus the emissions of modern aircraft. Driven by the related flow physics behind these techniques, new challenges arise for the field of aeroelasticity as discussed by Tichy et al. (2017). Since a transitional boundary layer flow is an inherent feature of laminar airfoils, the influence of various boundary layer effects like laminar-turbulent boundary layer transition and separation have to be considered when assessing the aeroelastic stability. Experimental investigations by Hebler (2017) as well as numerical investigations by van Rooij and Wegner (2014), Fehrs (2013) and Fehrs et al. (2015) showed that aeroelastic instabilities of a laminar airfoil occur earlier for a boundary layer with free transition than in a fully turbulent flow. In a 2D flutter experiment on a CAST 10-2 supercritical laminar airfoil model in the transonic flow regime, Braune and Hebler (2018) further showed that self-excited single degree of freedom (1-DoF) limit cycle oscillations (LCOs) in pitch occurred in the vicinity of the characteristic laminar drag bucket of the airfoil. This aeroelastic instability is directly connected to a boundary layer that can perform a free laminar-turbulent boundary layer transition. To resolve the unsteady behavior of the boundary layer during LCOs, the suction side of the wind tunnel model was equipped with 26 hot-film sensors that were operated by constant temperature anemometers (CTAs).

Since the first investigations by Liepmann and Skinner (1954) and Bellhouse and Schultz (1966), surface mounted hot-film sensors have become an established measurement technique for measuring wall shear stresses. The application of multiple hot-film sensor (MHFS) arrays for the largescale investigation of the boundary layer of bodies in flows is common as well and, due to the high dynamic response of the measurement technique, particularly suitable for the more precise characterization of instability mechanisms in boundary layers as it was done by Leuckert et al. (2011), for example.
Lee and Basu (1998) used MHFS to study the unsteady development of the boundary layer on an oscillating airfoil model at low Reynolds numbers. Further investigations of the unsteady boundary layer transition on pitching airfoils at higher Reynolds numbers, but for subsonic Mach numbers, were performed by Richter et al. (2013) and Richter et al. (2014). The transition position was detected by means of the root-mean-square (RMS) of the unfiltered voltage signals of each hot-film sensor. The same statistical methods in combination with a calculation of the skewness of the hot-film signals were applied by Mai and Hebler (2011) and Hebler et al. (2013) to investigate the unsteady behavior of the boundary layer on the CAST 10-2 laminar airfoil under transonic flow conditions. In all cases, a manual evaluation of the hot-film signals was carried out, which is very timeconsuming. Based on the skewness, Richter et al. (2015) and Richter et al. (2016) used an automated algorithm for the detection of unsteady laminar-turbulent boundary layer transition. The algorithm is described in more detail in Goerttler et al. (2017). This evaluation method was so far applied to cases with a low Mach number and without occurring compression shocks.

In this paper, the unsteady behavior of the boundary layer for a CAST 10-2 supercritical laminar airfoil is investigated, while the airfoil performs a 1-DoF LCO in pitch. The present boundary conditions, i.e., a transonic flow with a shock-boundary layer interaction as well as comparatively small oscillation amplitudes of less than $|\Delta \alpha|<1^{\circ}$ and a high oscillation frequency of $f_{\alpha} \approx 60 \mathrm{~Hz}$ of the LCO, deviate however significantly from the cases described above. Therefore, and in particular when the shock position is located close to a hot-film sensor, a statistical interpretation of the hot-film signals can only be done in a rough way. In addition, the physical view is lost, as now not only the boundary layer influences the hot-film signals. Shock and boundary layer separation also lead to a change of the signals and manual data interpretation therefore requires a lot of experience.

However, to provide a physically motivated criterion to identify the boundary layer states and in particular to automatically detect the laminar-turbulent boundary layer transition, an evaluation of the hot-films on the basis of the quasiwall shear stress, introduced by Hodson (1985), is presented here. On this basis, an algorithm has been developed which allows a mostly automated detection of the laminar-turbulent boundary layer transition even under the mentioned flow conditions. For steady and unsteady flows, as with a LCO, the boundary layer and the shock-boundary layer interaction of the laminar airfoil are resolved for a Mach number of $\mathrm{Ma}=0.73$ and a Reynolds number of $\operatorname{Re} \approx 2 \times 10^{6}$. In addition, a relation between the motion of the model and that of the boundary layer transition for transonic flow conditions is quantified here for the first time. 


\section{Experimental test setup}

The presented results were obtained by a $2 \mathrm{D}$ flutter experiment on a CAST 10-2 supercritical laminar airfoil model, carried out in the Transonic Wind Tunnel Goettingen (DNW-TWG). The measurements were performed in the adaptive test section of the DNW-TWG. By means of a two-dimensional adaptation of the upper and lower tunnel walls to the steady flow field, wall-induced perturbations were minimized. The measurements were performed in a Mach number range of $0.5 \leq \mathrm{Ma} \leq 0.8$ and a variable total pressure $p_{0}$ between 40 and $75 \mathrm{kPa}$, resulting in a chordbased Reynolds number of $1.15 \times 10^{6} \leq \operatorname{Re} \leq 2.83 \times 10^{6}$.

\subsection{Flutter experiment}

A CAST 10-2 laminar airfoil model with a chord length of $c=0.3 \mathrm{~m}$ and a span of $s=0.997 \mathrm{~m}$ was elastically mounted into a flutter test rig, which was previously used by Dietz et al. (2006). The model was made of carbon fiber composites in shell construction and connected to the experimental test rig via two aluminium bases at $x / c=0.25$. The test rig consists of two spring systems (each built up from two plate springs and a torsion spring), one on each side of the wind tunnel walls. This allows the airfoil model to perform motions with the two degrees of freedom heave and pitch. In the present results, the heave springs were mechanically locked so that an aeroelastic system with a single experimentally specified degree of freedom was provided. The model was thus able to perform self-excited pitching oscillations around $c / 4$. The relevant mass moment of inertia of all oscillating components including the wind tunnel model was $I_{\alpha} \approx 0.065 \mathrm{~m} \times \mathrm{s}^{2}$, related to $c / 4$. The wind off eigenfrequency was $47.7 \mathrm{~Hz}$, the corresponding damping coefficient was $D_{\alpha} \approx 0.39 \%$.

The flutter test rig was integrated into the $2 \mathrm{D}$ support of the DNW-TWG, which enables rotation of the entire test rig including the wind tunnel model. In this way, the mean angle of attack $\alpha$ was adjusted and kept constant during the measurements, hence changes of the angle of attack due to the elastic suspension and varying aerodynamic pitching moments under changed flow conditions could be compensated as well. During the flutter tests, the mean angle of attack was preset to $\alpha \approx 0^{\circ}$, so that flutter measurements were performed directly within the characteristic laminar drag bucket of the airfoil model (see Fig. 6). A sketch of the test setup is depicted in Fig. 1.

Safety systems such as brakes and a flutter control system, both attached to the flutter test rig, enable investigations of aeroelastic systems at the stability limit and even

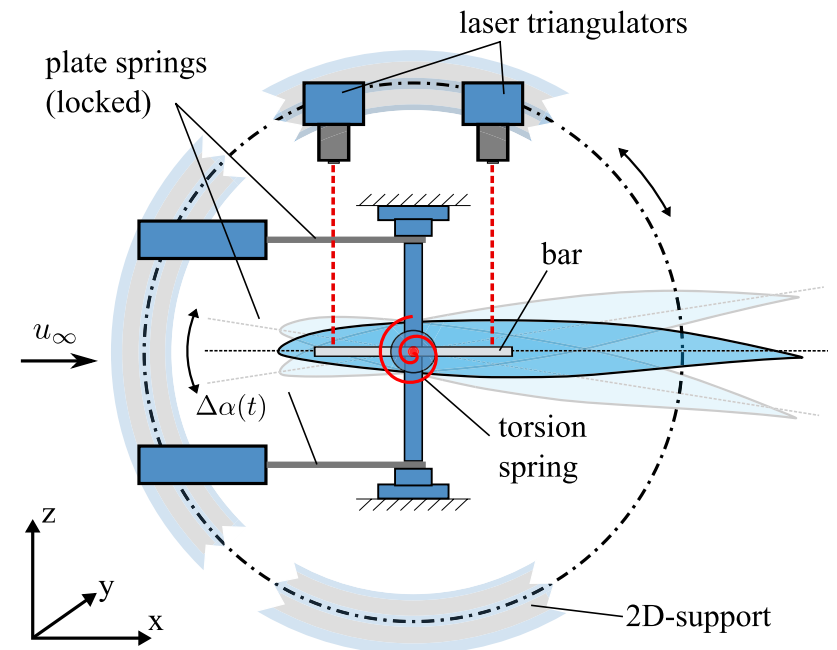

Fig. 1 Experimental test setup for 1-DoF flutter in pitch, based on Braune and Hebler (2018)
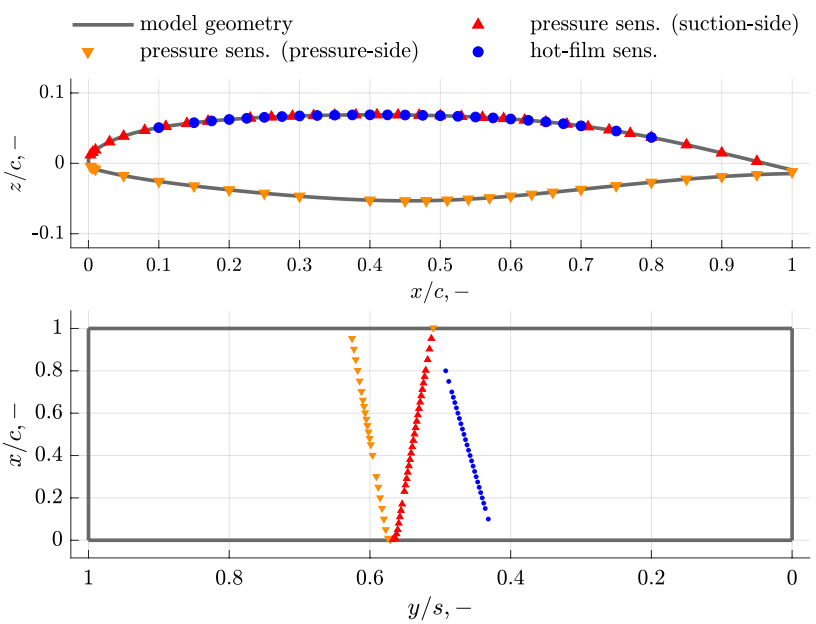

Fig. 2 Geometry of the CAST 10-2 wind tunnel model and distribution of pressure and hot-film sensors, based on Braune and Hebler (2018). The coordinate system corresponds to that of the DNWTWG, the inflow is along the $x$-axis

beyond. So also LCOs or flutter with high growth rates in amplitude could be observed and recorded directly.

The pitch motion $\Delta \alpha(t)$ of the wind tunnel model was measured by four laser triangulators (Micro-Epsilon optoNCDT 1605 with LD 1605-20) pointing at target bars attached to the model. The accuracy was less than $0.02^{\circ}$. Aerodynamic forces and moments were calculated by a chordwise integration of the pressure distribution, obtained by 60 unsteady, temperature-compensated differential pressure sensors (Kulite XCQ-093D) mounted into the model (see Fig. 2). They were also used for the detection of compression shocks. All sensor data mentioned so far were acquired simultaneously with a data acquisition system (Dewetron 
DEWE-818 with DEWE-51-PCI-128) at a sampling frequency of $2.4 \mathrm{kHz}$.

\subsection{Hot-film anemometry}

To resolve the unsteady behavior of the boundary layer, the suction side of the wind tunnel model is equipped with a MHFS array (customized Senflex hot-film sensors, Tao of Systems Integration, Inc.), consisting of 26 hot-film sensors that were operated by multiple CTAs. The CTAs were developed and provided by the DLR-Institute of Aerodynamics and Flow Technology. Each sensor is integrated into a Wheatstone bridge circuit, where it is set to an operating resistance $R_{\mathrm{S}}$ and thus heated to an operating temperature $T_{\mathrm{S}}$. The bridge is aligned. Due to changing flow conditions, hence a changed heat transfer, the resistance of the hot-film sensor changes and an imbalance of the bridge is generated. The anemometer electronics restores the alignment of the bridge by changing the bridge voltage $U$. If the gain of the anemometer is sufficiently high, the equilibrium of the bridge is restored immediately and the sensor resistance or temperature is kept constant. Each sensor consists of a $0.2 \mu \mathrm{m}$-thin nickel film with $1.45 \mathrm{~mm}$ length and $0.1 \mathrm{~mm}$ width. The sensors are deposited onto a polyimide foil with a thickness of $50 \mu \mathrm{m}$ and connected to the CTA-system by copper-coated leads. The MHFS substrate foil was applied to a recess (depth $100 \mu \mathrm{m})$ in the upper side of the model using double-sided adhesive tape (thickness $50 \mu \mathrm{m}$ ). The recess was dimensioned according to the foil dimensions. The remaining gaps were filled and sanded to ensure a formfit and flush transition. The cabling of the hot-films was done via the inside of the model, so that the MHFS array does not disturb the boundary layer. The measurement technique can therefore be regarded as non-intrusive, which was additionally monitored and checked with an infrared camera during testing.

Figure 2 shows the distribution of the pressure and hotfilm sensors on the wind tunnel model. The pressure sensors are mounted near the middle section around the entire profile at an angle of $10^{\circ}$ to the flow to prevent the pressure holes from interfering with each other. The hot-film sensors are installed on the suction side of the model. From $x / c=0.15$ to $x / c=0.7$ the sensors are equally spaced at a distance of $\Delta x / c=0.025$. Another sensor is positioned near the leading edge at $x / c=0.1$ and two sensors are located downstream at $x / c=0.75$ and $x / c=0.8$. Their layout is also staggered at an angle of $10^{\circ}$ to avoid mutual interference by the temperature boundary layers of the individual sensors.

The hot-film sensors have a nominal resistance $R_{0}$ of approximately $9.1 \Omega$ at ambient temperature. The overheat ratio $a=\frac{R_{\mathrm{S}}}{R_{0}}$ was set to 1.3 , so the heated hot-films reached a temperature difference to the ambient temperature $T_{\mathrm{a}}$ of
$\Delta T=T_{\mathrm{S}}-T_{\mathrm{a}} \approx 100 \mathrm{~K}$. The resistances and thus the overheating ratio of each hot-film sensor were checked each morning and adapted to the current ambient temperatures to ensure constant test conditions for all sensors.

To utilize the full sampling frequency, a square wave test was carried out before each measuring day. Thereby, the stability of the CTA circuits was proved and the sensors were adjusted to high cut-off frequencies of approximately $60 \mathrm{kHz}$. Thus a uniform dynamic behavior of the sensors was ensured. The voltage signals of the CTAs were recorded with a separate data acquisition system (Dewetron DEWE818 with DEWE-51-PCI-128) at a sampling frequency of $120 \mathrm{kHz}$. Both data acquisition systems, one for the CTAs and the second for all other sensors were synchronized in time. Since the hot-films and pressure sensors (amongst others) were recorded simultaneously, but with a different sampling frequency, every fiftieth data point of the CTA system was recorded at the same time as the other sensors.

During a test run, the respective voltage signals of the CTAs were recorded. At the same time, the ambient temperature was measured, which is subject to fluctuations of up to $10 \mathrm{~K}$ during a measurement series despite cooling of the wind tunnel. In addition, the zero voltages $U_{0}$ of the hotfilm sensors in the heated state without inflow were recorded before and after each measurement series. These voltage signals are necessary for further data processing, which is described next.

\section{Theoretical overview and data processing}

This section presents the theoretical background of the hot-film anemometry technique to describe the relation between the sensor signals and the state of the boundary layer. Because of practical reasons, a calibration of the hotfilm array was not possible within the experimental context presented here; quantitative wall shear stress measurements were not performed. For this purpose, the quasi-wall shear stress is introduced, which allows at least a qualitative and physically motivated interpretation where the boundary layer transition occurs and also provides an indication where a separation of the boundary layer takes place.

\subsection{Relation of heat transfer and wall shear stress}

The theoretical principle of the hot-film anemometry technique is based on the Reynolds analogy, i.e., the correlation of impulse and heat transfer in viscous flows. Thus a connection between the local wall shear stress $\tau_{\mathrm{w}}$ and the heat transfer $\dot{Q}_{\mathrm{F}}$ from a hot-film sensor to the flow can be established. The total heat transfer is again determined by the supplied electrical power $P(t)=\frac{U(t)^{2}}{R_{\mathrm{S}}}$ to the hot-film sensor 
and the temperature difference $\Delta T$. Thus, the wall shear stress can be expressed as a function of the CTA voltage signal $U(t)$ formulated by Bellhouse and Schultz (1966) as

$\tau_{\mathrm{w}}=A\left(\frac{U(t)^{2}-B^{2}}{\Delta T}\right)^{3}$.

$A$ and $B$ are functions of the temperature difference $\Delta T$. Considering only small variations of $\Delta T, A$ and $B$ can be assumed as constants. ${ }^{1}$ For a quantitative measurement of the wall shear stress by hot-film anemometry, these constants would have to be determined by a calibration.

\subsection{Quasi-wall shear stress}

For the present experimental setup, a calibration of the MHFS array was not performed. So, only qualitative values for the wall shear stress are provided by the hot-film sensors. To provide at least semi quantitative values for $\tau_{\mathrm{w}}$ and thus enable a physical motivated interpretation of the measurement results with respect to the boundary layer, the so-called quasi-wall shear stress $\tau_{\mathrm{q}}$, as introduced by Hodson (1985) and Hodson et al. (1994), is used.

Equation (1) can be converted into an expression which behaves in a similar way as the real wall shear stress. Therefore, the constant $B$ is replaced by the zero voltage $U_{0}$ of the hot-film sensors. The wall shear stress must be zero if there is no inflow. Consequently, the quasi-wall shear stress should also satisfy this requirement. As $A \neq 0$ and $\Delta T$ will not go to infinity, for practical reasons, this is satisfied by $U(t)^{2}-B^{2}=0$. Since $U(t)=U_{0}$ without flow, $B^{2}=U_{0}^{2}$. In addition, $\dot{Q} \sim \Delta T$ generally applies. This means, that $\dot{Q}_{\mathrm{F}}$ is proportional to the temperature difference between the heated hot-film and the fluid. The (further) heat transfer $\dot{Q}_{\mathrm{S}}$ between hot-film and substrate, i.e., the wind tunnel model, is also proportional to $\Delta T$, which is now related to the temperature of the model. Assuming that the model temperature equals the ambient air temperature, which is normally the case, $U(t)^{2}=R_{\mathrm{S}}\left(\dot{Q}_{\mathrm{F}}+\dot{Q}_{\mathrm{S}}\right) \sim \Delta T$ follows. Since the temperature difference already exists without inflow, $\Delta T \sim U_{0}^{2}$. Thus, Eq. (1) can be approximated by the semi-quantitative representation

$\tau_{\mathrm{w}} \sim \tau_{\mathrm{q}}=\left(\frac{U(t)^{2}-U_{0}^{2}}{U_{0}{ }^{2}}\right)^{3}$,

as it was used by Hodson et al. (1994). A calibration is no longer necessary since all constants have been replaced by directly measurable quantities. The relationship between $\tau_{\mathrm{q}}$

${ }^{1}$ Note the similarity of Eq. (1) to King's law (King and Barnes 1914), which is often used in hot-wire anemometry. and $\tau_{\mathrm{w}}$ is not exact, but the quasi wall shear stress and the real wall shear stress behave in a similar way and can therefore be equally interpreted as described below.

\subsection{Indication of boundary layer transition}

The wall shear stress $\tau_{\mathrm{w}}$ is proportional to the wall normal velocity gradient at the surface. Since the velocity gradient is influenced by a laminar-turbulent boundary layer transition, $\tau_{\mathrm{w}}$ is also affected. The wall shear stress and thus $\tau_{\mathrm{q}}$ show a characteristic trend indicating a boundary layer transition.

For a laminar boundary layer, the boundary layer thickness $\delta$ increases with increasing running length $x$. The velocity gradient close to the wall decreases and so does $\tau_{\mathrm{w}}$ or $\tau_{\mathrm{q}}$. As a boundary layer transition occurs, $\delta$ grows significantly. In comparison with a laminar boundary layer, the flow velocities directly above the surface are significantly higher due to the strong mixing in the turbulent boundary layer. Since the no-slip condition is still satisfied, there is a small viscous sublayer with a velocity gradient near the wall that is strongly increased, resulting in high values of $\tau_{\mathrm{w}}$ or $\tau_{\mathrm{q}}$. The growth of the boundary layer and the viscous sublayer again leads to a reduction of the wall shear stress with increasing $x$. This means that a strong increase of the quasi-wall shear stress $\tau_{\mathrm{q}}$ is an indication of a boundary layer transition and can therefore be used for transition location determination, as described in the following section. Exemplary curves of the quasi-wall shear stress can be seen in Fig. 4. The strength of the increase also provides indications of the cause of the transition. This is particularly the case if the boundary layer undergoes a transition due to a compression shock. The strong pressure rise leads to a fast increase of $\tau_{\mathrm{q}}$, whereas a longer transition process leads to a slower one, which can also be seen by comparing Fig. 4a, b.

In addition, a boundary layer separation is indicated by a vanishing wall shear stress. If, for example, a laminar separation bubble is formed, the near wall flow direction reverses, thus $\tau_{\mathrm{w}}<0$. Due to the similarity of $\tau_{\mathrm{q}}$ to $\tau_{\mathrm{w}}$, the course of $\tau_{\mathrm{q}}$ can also be used to provide indications of a possible boundary layer separation. Theoretically, this would also be indicated by a zero crossing and a negative value of $\tau_{\mathrm{q}}$. Since the hot-film sensors are not sensitive to a flow direction, separated areas with unsteady velocity profiles and fluctuating flow directions lead to an increased heat transfer compared to the zero state. Therefore, in practice, the quasi-wall shear stress is greater than zero. However, areas in which the quasi-wall shear stress is close to zero can be an indication of separation. On the basis of non-calibrated hot-film sensors, it is difficult to find clear evidence for a boundary layer separation and is therefore preferably supported by other methods such as a pressure distribution $c_{\mathrm{p}}(x)$ (see Fig. 4b). 


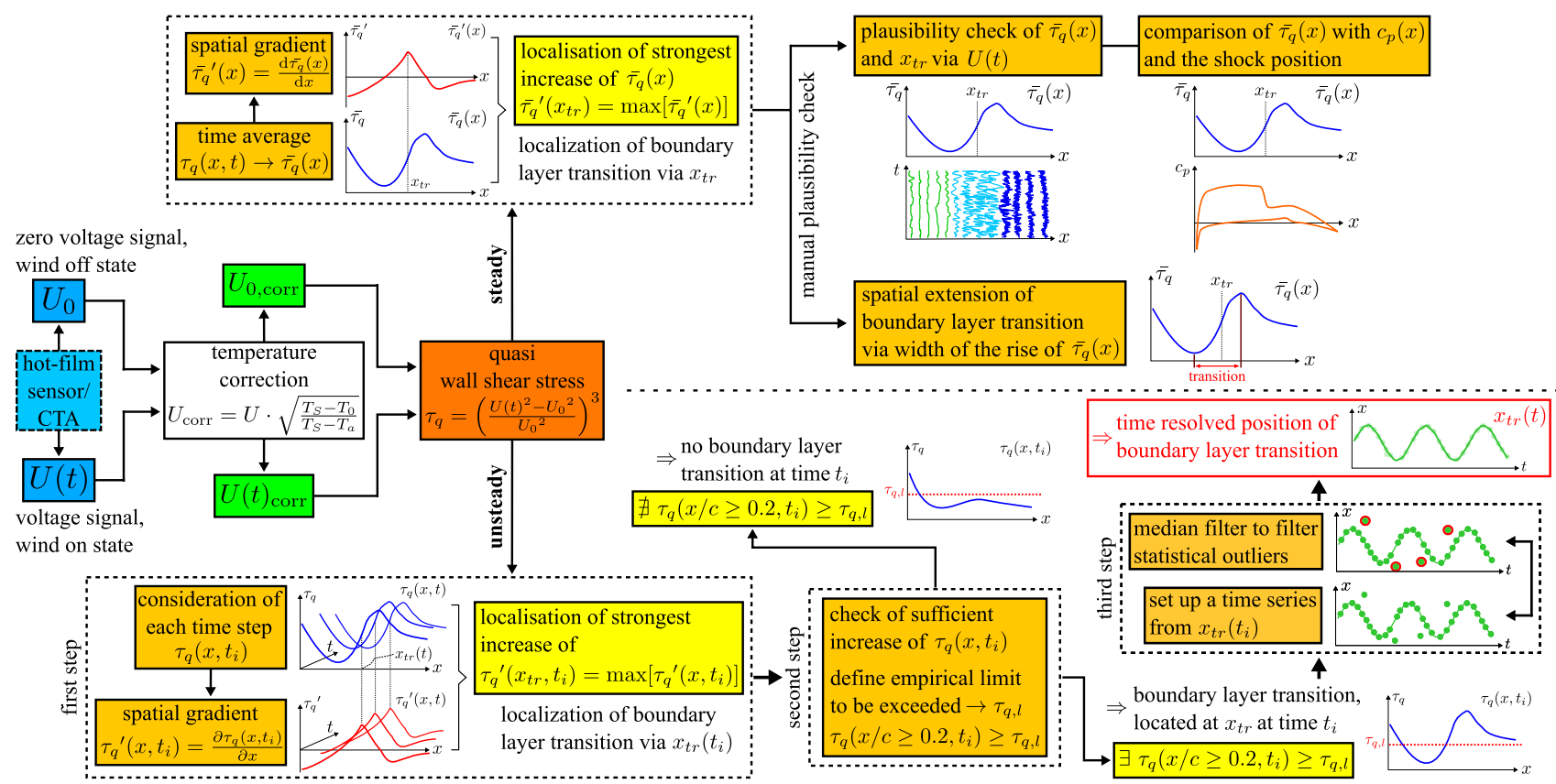

Fig. 3 Flowchart to explain the data processing of the hot-film signals and the detection of the laminar-turbulent boundary layer transition for steady and unsteady measurements based on the quasi-wall shear stress

\subsection{Data processing}

The data processing of the hot-film signals to obtain the quasi-wall shear stress $\tau_{\mathrm{q}}$ and the methodology to detect the laminar turbulent boundary layer transition are schematically illustrated in Fig. 3 by means of a flowchart diagramm.

During the wind tunnel experiments of a single day the facility warms up. As a result, the hot-film sensors are exposed to different ambient temperatures $T_{\mathrm{a}}$ and the temperature difference $\Delta T$ varies as $T_{\mathrm{S}}$ is constant. To compensate for these changes, a temperature correction

$U_{\text {corr }}=U \times \sqrt{\frac{T_{\mathrm{S}}-T_{0}}{T_{\mathrm{S}}-T_{\mathrm{a}}}}$

specified by Hultmark and Smits (2010) is applied to the measured voltage signals $U(t)$ and to the zero voltages $U_{0}$ of the CTA anemometers. It is assumed that changes of the flow properties due to the temperature change are negligible. The reference temperature $T_{0}$ used for this is the ambient temperature that was present at the last setting of the overheating ratio of the MHFS array. The corrected voltage signals $U_{\text {corr }}$ are then converted into quasi-wall shear stresses $\tau_{\mathrm{q}}$ using Eq. (2). Based on $\tau_{\mathrm{q}}$, the detection of the laminar turbulent boundary transition is performed, whereby the procedure depends on whether steady-state measurements (fixed wind tunnel model, steady flow) or unsteady measurements (moving wind tunnel model, unsteady flow) are involved.
For steady measurement series, the sensor signals were recorded over a period of nearly $17 \mathrm{~s}$. After the data processing described above, using the full sampling rate of $120 \mathrm{kHz}$, the signals are time-averaged to obtain $\bar{\tau}_{\mathrm{q}}(x)$. To quantify the fluctuation margin, the standard deviation and the minimum and maximum values ${ }^{2}$ are also determined (not shown in Fig. 3). The spatial gradient $\bar{\tau}_{\mathrm{q}}$ ' of the mean quasi-wall shear stress along the chord $x$ is calculated and an identification of the maximum

$\bar{\tau}_{\mathrm{q}}^{\prime}(x)=\frac{\mathrm{d} \bar{\tau}_{\mathrm{q}}(x)}{\mathrm{d} x}, \quad \bar{\tau}_{\mathrm{q}}{ }^{\prime}\left(x_{\mathrm{tr}}\right)=\max \left[\bar{\tau}_{\mathrm{q}}{ }^{\prime}(x)\right]$,

localized at $x_{\mathrm{tr}}$, is performed. The strongest increase of the quasi-wall shear stress thus determined is used to localize the laminar-turbulent boundary layer transition. In general, the maxmimum of $\bar{\tau}_{\mathrm{q}}{ }^{\prime}(x)$, thus $x_{\mathrm{tr}}$ correlates quite well with the transition position. However, it is possible that, for example, a compression shock leads to a second increase of $\bar{\tau}_{\mathrm{q}}(x)$, which is incorrectly determined as transition position. To exclude this a manual plausibility check of the quasi-wall shear stress is carried out. This is done on the basis of a

\footnotetext{
2 The minimum and maximum values are estimated by the mean values of the envelopes of the time series $\tau_{\mathrm{q}}(x, t)$, which are obtained by identifying the peaks and smoothing over 1000 neighboring local maximums or minimums. This method is used to not overestimate individual strong signal outliers which may represent electrical and thus non-physical distortions.
} 


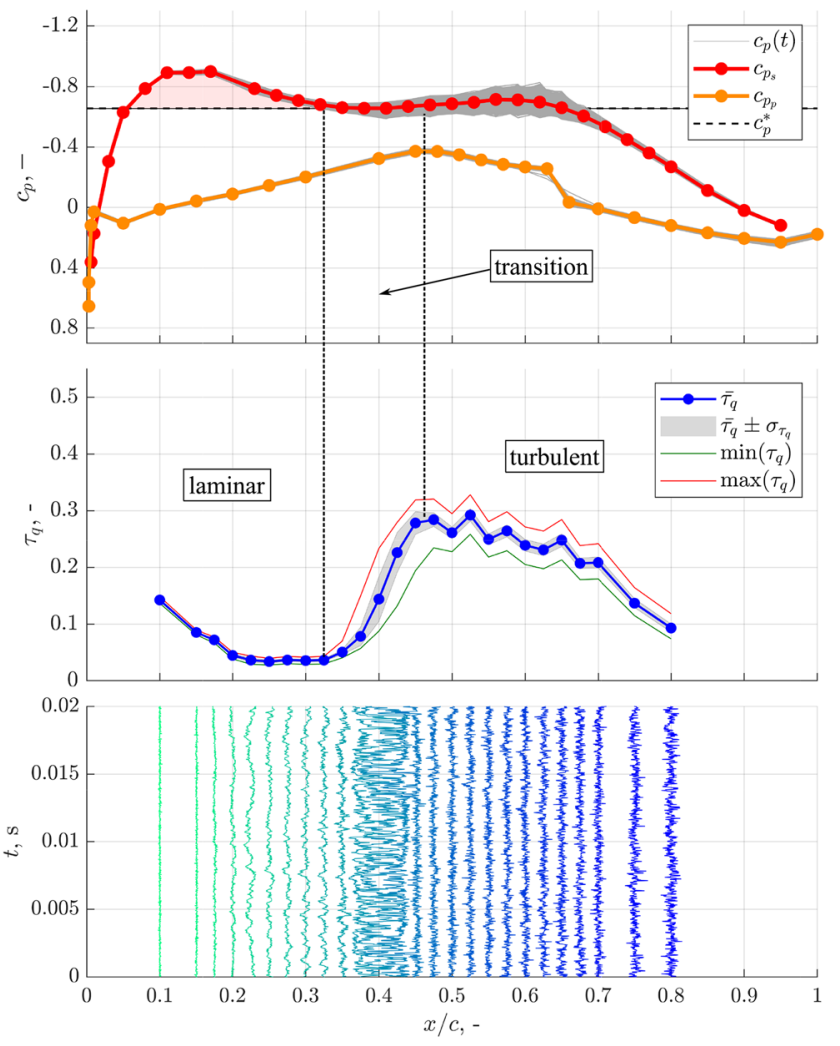

(a) $\mathrm{Ma}=0.73, \operatorname{Re} \approx 2 \cdot 10^{6}$ and $\alpha \approx 0^{\circ}$

Fig. 4 Pressure distributions $c_{\mathrm{p}}\left(c_{p_{\mathrm{s}}}\right.$ corresponds the suction side and $c_{p_{\mathrm{p}}}$ to the pressure side of the laminar airfoil), trend of the quasi-wall shear stress $\bar{\tau}_{\mathrm{q}}(x)$ and time sections of the corresponding voltage signals (scaled by 0.5 ) of the CTAs for a free boundary layer transition (a) and due to shock-boundary layer interaction (b). The red

composite representation of the time series of the voltage signals $U(t)$ from the hot-film sensors as well as the pressure distribution $c_{\mathrm{p}}(x)$. If necessary, a manual correction of $x_{\mathrm{tr}}$ could be made. The spatial extent of the transition is not considered by this method. This can be obtained from the width of the rise of $\bar{\tau}_{\mathrm{q}}(x)$. The beginning of the rise also marks the beginning of the transition and the end of the rise the end of the transition process, as it can be seen exemplarily in Fig. 4.

The potential of the quasi-wall shear stress becomes much more apparent in the case of unsteady measurements. A detection of the time-dependent position of the laminar-turbulent boundary layer transition is significantly more complicated. A manual evaluation of hot-film data is no longer possible due to the large amount of data. In this case the calculated time series of the quasi-wall shear stress $\tau_{\mathrm{q}}(x, t)$ is considered directly and an evaluation of each time step $\tau_{\mathrm{q}}\left(x, t_{i}\right)$ is performed. To realize an automated detection and marking of the unsteady position of the boundary layer transition, a three-step algorithm is applied.

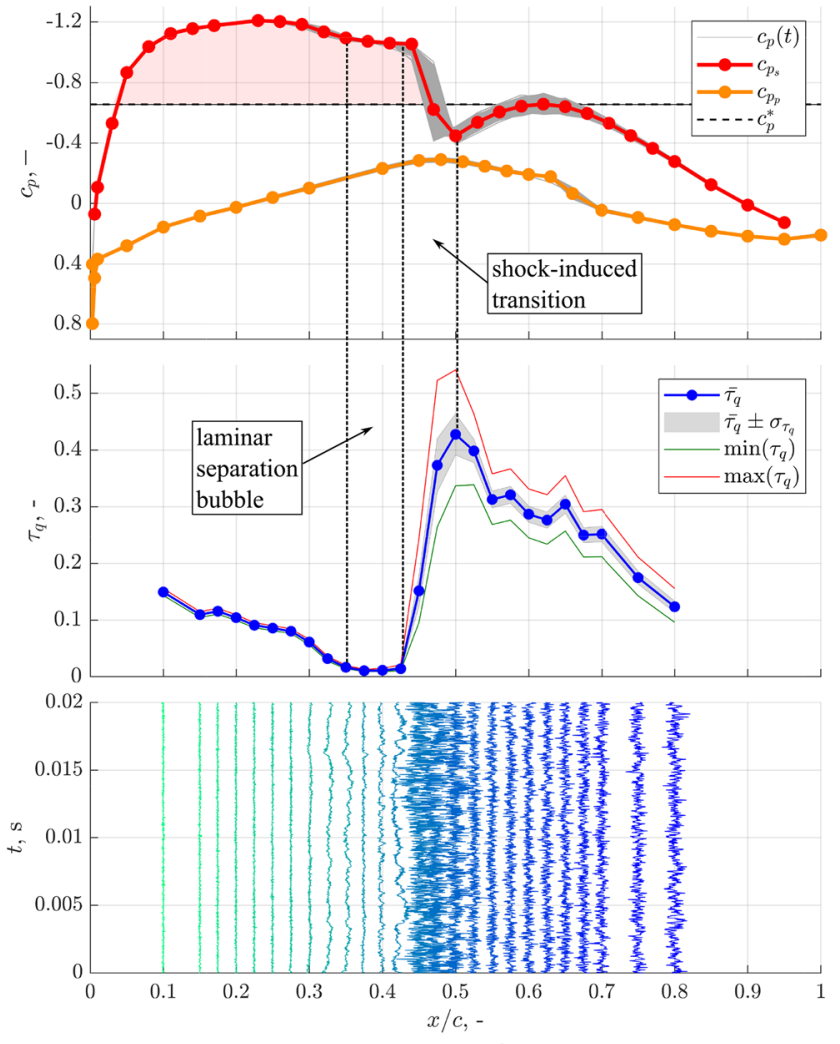

(b) $\mathrm{Ma}=0.73, \operatorname{Re} \approx 2 \cdot 10^{6}$ and $\alpha \approx 1.2^{\circ}$

highlighted areas indicate supersonic regions, $c_{\mathrm{p}}{ }^{*}$ denotes the critical pressure coefficient and $c_{\mathrm{p}}(t)$ the superposition of the measured time series for $c_{\mathrm{p}}$. To resolve the fluctuations of $\tau_{\mathrm{q}}$, in addition to the timeaveraged $\bar{\tau}_{\mathrm{q}}$, the standard deviation $\bar{\tau}_{\mathrm{q}} \pm \sigma_{\tau_{\mathrm{q}}}$ as well as the minimum and maximum values are plotted

In the first step, the spatial gradient $\tau_{\mathrm{q}}{ }^{\prime}\left(x, t_{i}\right)=\frac{\partial \tau_{\mathrm{q}}\left(x, t_{i}\right)}{\partial x}$ is calculated analogous to Eq. (4). The position of the strongest increase $\tau_{\mathrm{q}}{ }^{\prime}\left(x_{\mathrm{tr}}, t_{i}\right)=\max \left[\tau_{\mathrm{q}}{ }^{\prime}\left(x, t_{i}\right)\right]$ is localized for time $t_{i}$. As before, it is assumed that $x_{\mathrm{tr}}\left(t_{i}\right)$ correlates with the position of the boundary layer transition.

In some cases a boundary layer transition does not occur within the sensor range and a laminar boundary layer is present. The quasi-wall shear stress thus shows no significant increase. Slight increases of $\tau_{\mathrm{q}}$ may occur though, which are misinterpreted as transition in the first step. These incorrect transition positions are removed in the second step by requiring $\tau_{\mathrm{q}}\left(x, t_{i}\right)$ to reach or exceed an empirically defined threshold value $\tau_{\mathrm{q}, 1}$. For convenience only values $\tau_{\mathrm{q}}(x / c \geq 0.2)$ are considered in this step. For the cases presented in the following, this threshold is set to $\tau_{\mathrm{q}, \mathrm{l}}=0.065$. If no $\tau_{\mathrm{q}}\left(x / c \geq 0.2, t_{i}\right)$ exists that satisfies the sufficient condition $\tau_{\mathrm{q}}\left(x / c \geq 0.2, t_{i}\right) \geq \tau_{\mathrm{q}, 1}$, the transition position $x_{\mathrm{tr}}\left(t_{i}\right)$ determined in the first step is rejected and a laminar boundary layer is assumed. If $\tau_{\mathrm{q}}\left(x, t_{i}\right)$ exceeds the 
threshold value, there usually is a boundary layer transition at the position $x_{\mathrm{tr}}$ at time $t_{i}$.

The positions $x_{\mathrm{tr}}\left(t_{i}\right)$ thus obtained can now be combined to a time series $x_{\mathrm{tr}}(t)$. This time series shows isolated outliers, which are filtered out in the third step. Such outliers are caused, among other things, by a double shock system, as it occurs with the laminar airfoil for slightly higher Mach numbers than shown here. There may be two significant rises of $\tau_{\mathrm{q}}(x)$, but only the first one is associated with the boundary layer transition. The second one can be misinterpreted as a transition position, leading to isolated discontinuities of $x_{\text {tr }}$. These are physically justified, but they are not related to the laminar-turbulent boundary layer transition and are filtered out by the algorithm. Overshoots in the trend of $\tau_{\mathrm{q}}\left(x, t_{i}\right)$ can also lead to wrong transition positions in the first step. Without receiving any greater physical significance, they are also removed. All these outliers can be treated as statistical outliers and are filtered by a median filter, ${ }^{3}$ which is applied to $x_{\text {tr }}(t)$.

This method offers the possibility of extracting a timeresolved transition position even from large unsteady measurements, also in cases where a transonic flow and a shock-boundary layer interaction are present. It allows the quantitative detection of the unsteady transition movement $x_{\mathrm{tr}}(t)$, as shown in the following example for the laminar airfoil undergoing a LCO.

\section{Results and discussion}

In this section results of the evaluation of the MHFS array signals for steady and unsteady measurements are presented. First, the boundary layer behavior for the fixed mounted laminar airfoil, so for steady flow is considered. In the following, an unsteady case is analyzed in which the laminar airfoil model performs a 1-DoF LCO in pitch. In this context, the estimation of the movement of the laminar-turbulent boundary layer transition depending on the motion of the airfoil itself is of great interest. At last, the unsteady transition in combination with the interaction of a compression shock during the LCO is summarized and discussed from the described results.

\subsection{Boundary layer transition on the steady airfoil}

The steady hot-film results were obtained prior to the flutter tests by measuring the lift and moment curves $c_{1}(\alpha)$ and

\footnotetext{
${ }^{3}$ It should be noted that the window length of the median filter should be as small as possible to achieve reliable outlier suppression but to avoid significant signal suppression. Furthermore, a too large window size leads to a phase distortion of $x_{\mathrm{tr}}(t)$.
}

$c_{\mathrm{m}}(\alpha)$ of the laminar airfoil presented in Braune and Hebler (2018). The measurements were conducted at different Mach numbers for a Reynolds number of $\operatorname{Re} \approx 2 \times 10^{6}$. To get an impression of how the quasi-wall shear stress reflects boundary layer transition and provides an indication of laminar separation bubbles, two representative measurement points are chosen. The flow conditions $\mathrm{Ma}=0.73$ and $p_{0}=54 \mathrm{kPa}$ represent those conditions where the laminar airfoil experienced 1-DoF LCOs in pitch (Braune and Hebler 2018). For this purpose, the pressure distribution and the measured quasi-wall shear stress on the airfoil's suction side are depicted in Fig. 4. For further comparison, time sections of the corresponding voltage signals $U(t)$ of the CTAs are shown.

The first case, shown in Fig. 4a, corresponds to an angle of attack of $\alpha \approx 0^{\circ}$ at which no compression shock occurs. Up to $x / c \approx 0.2$ the quasi-wall shear stress drops and the voltage signals of the hot-film sensors show no significant fluctuations, corresponding to a laminar boundary layer. The pressure gradient becomes positive downstream of $x / c \approx 0.2$, which seems to destabilize the boundary layer. The value of $\tau_{\mathrm{q}}$ stays at a constant, small level, but is clearly greater than zero. This trend does not give an indication for a separation of the boundary layer. The pressure distribution does not provide any indication of this either. The voltage signals of the hot-films show small fluctuations that cannot be clearly classified but do not correspond to a laminar-turbulent transition. The transition process itself begins at a location more downstream and is indicated by an increase of the quasi-wall shear stress, starting roughly at $x / c \approx 0.33$ and ends at $x / c \approx 0.48$. This also defines the transition area depicted in Fig. 4a and is supported by the strong fluctuations of the CTA voltage signals. The fluctuations as well as the minimums and maximums of the quasi-wall shear stress also increase. This indicates the increase of unsteadiness within the boundary layer due to turbulent mixing, which in turn leads to the apparent temporal fluctuation of the pressure distribution on the suction side of the laminar airfoil and vice versa. For a turbulent boundary layer, i.e., after the transition process is completed, $\tau_{\mathrm{q}}$ decreases, as it is the case downstream from $x / c \approx 0.48$. The voltage signals of the CTAs show fast but in their amplitude limited fluctuations in this region.

The second case, shown in Fig. $4 \mathrm{~b}$, corresponds to $\alpha \approx 1.2^{\circ}$. A pronounced supersonic area occurs downstream of the leading edge, which closes with a compression shock at $x / c \approx 0.45$. In the pressure distribution of the airfoil's suction side $c_{\mathrm{p}, \mathrm{s}}$ a plateau appears directly before the shock. The pressure remains constant, which indicates a laminar separation bubble forming around $x / c \approx 0.4$. Up to $x / c \approx 0.35$ the quasi-wall shear stress drops and to $x / c \approx 0.43$ it is close to zero, which corresponds to the expectations for $\tau_{\mathrm{q}}$ described in Sect. 3.3 in case of a separation. The spatial extent of the 


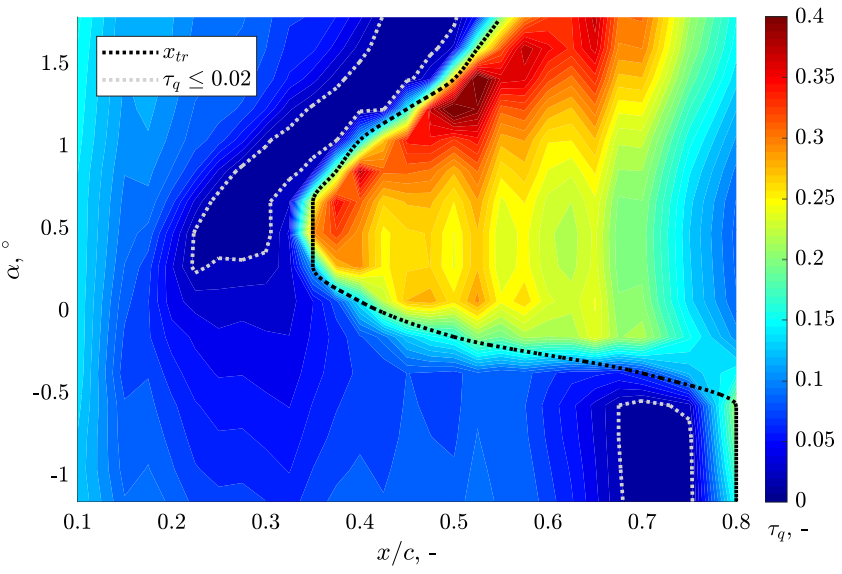

(a) $\tau_{q}(x / c, \alpha)$

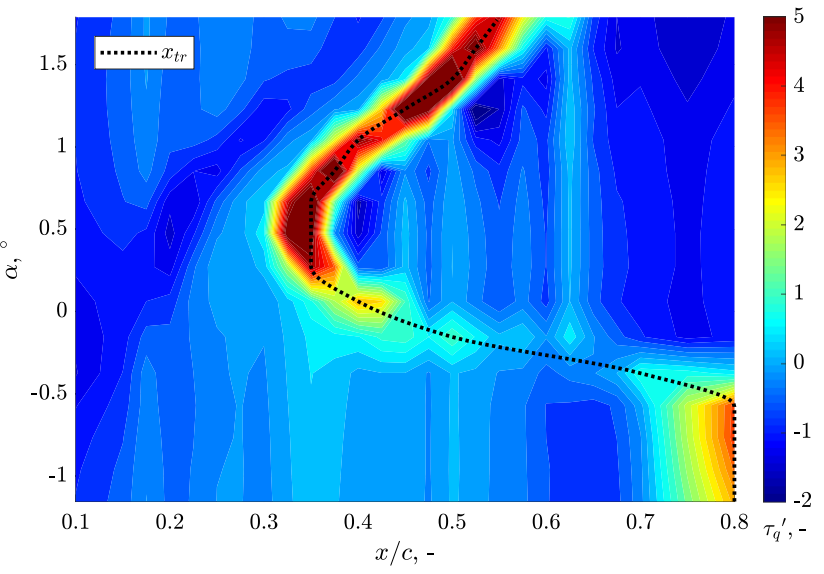

(b) $\tau_{q}{ }^{\prime}(x / c, \alpha)$

Fig. 5 Distribution of the quasi-wall shear stress $\tau_{\mathrm{q}}(x / c, \alpha)(\mathbf{a})$ and the spatial gradient $\tau_{\mathrm{q}}{ }^{\prime}(x / c, \alpha)(\mathbf{b})$ for Ma $=0.73$ and $\operatorname{Re} \approx 2 \times 10^{6}$. The trend of the boundary layer transition $x_{\mathrm{tr}}(\alpha)$ based on the gradient maximum as well as areas where $\tau_{\mathrm{q}} \leq 0.02$ are marked

laminar separation bubble is determined in Fig. 4b by the extent of the pressure plateau and the area where $\tau_{\mathrm{q}}$ is close to zero. ${ }^{4}$

The boundary layer transition is located directly behind the separation bubble and induced by the compression shock. This coincides with high amplitude fluctuating voltage signals from the hot film sensors. The shock-boundary layer interaction leads to a strong and fast increase of $\tau_{\mathrm{q}}$. As before, pronounced fluctuations of $\tau_{\mathrm{q}}$ occur. These are mainly due to a shock motion, as can be seen in the pressure distribution by $c_{\mathrm{p}}(t)$. Furthermore, the high values of $\max \left(\tau_{\mathrm{q}}\right)$ indicate, that the shock position partially coincides directly with the position of a hot-film sensor, leading to large amplitudes of $\tau_{\mathrm{q}}$. Downstream of the transition $\tau_{\mathrm{q}}$ drops, as expected, with increasing running length.

Figure 5a now shows $\tau_{\mathrm{q}}$ for an extended angle of attack range for $\mathrm{Ma}=0.73$ and $\mathrm{Re} \approx 2 \times 10^{6}$ to illustrate the influence of $\alpha$ on the transition location. For convenience, $\tau_{\mathrm{q}}(x / c, \alpha)$ is presented by color-coded contour plots. Besides, the spatial gradient $\tau_{\mathrm{q}}{ }^{\prime}(x / c, \alpha)$ is shown in Fig. $5 \mathrm{~b}$ to localize the laminar-turbulent boundary layer transition, as mentioned in Sect. 3.4. The transition is marked by a black dotted line in Fig. 5, based on an estimation of $x_{\mathrm{tr}}$ by Eq. (4). In addition, areas in which $\tau_{\mathrm{q}}$ is below an empirically determined value of 0.02 , i.e., close to zero, are enclosed by a grey dashed line. As previously shown in Fig. $4 \mathrm{~b}$ and

\footnotetext{
${ }^{4}$ The pressure plateau is related to the laminar part of the separation bubble, whereas the turbulent part of the bubble lies behind the plateau and coincides with a pressure recovery (Roberts 1980; Lee et al. 2015 among others). $\tau_{\mathrm{q}}$ already increases at the end of the plateau of $c_{\mathrm{p}, \mathrm{s}}$, indicating a reattached shear layer. A clear spatial restriction of the laminar separation bubble is therefore subject to uncertainty.
}

discussed in Sect. 3.3, these areas provide an indication of a potential boundary layer separation.

Up to an angle of attack of about $-0.6^{\circ}$ the transition is near the trailing edge where it correlates with a strong pressure increase at $x / c \approx 0.75$ not shown here. Upstream, areas with values of $\tau_{\mathrm{q}}$ near zero appear, as marked in Fig. 5a, providing an indication of a possible laminar separation bubble. An increase of $\alpha$ then leads to a rapid movement of the boundary layer transition upstream. This starts at an angle of attack of about $-0.4^{\circ}$ and correlates with the rapid drag increase, which appears in the drag polar shown in Fig. 6. The transition moves upstream to $x / c \approx 0.35$ and remains fixed at this location in an range of $0.2^{\circ} \lesssim \alpha \lesssim 0.8^{\circ}$. For larger angles the transition moves downstream again. From $\alpha \approx 0.2^{\circ}$ a compression shock occurs so that the transition is shock-induced beyond this

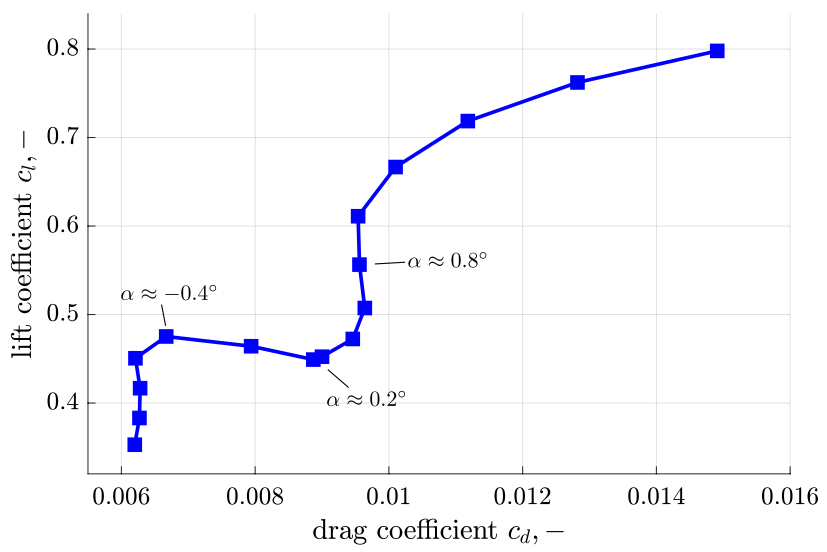

Fig. 6 Drag polar for the laminar aifoil model for $\mathrm{Ma}=0.73$, based on Braune and Hebler (2020). The angles of attack at which the flow changes significantly are marked 


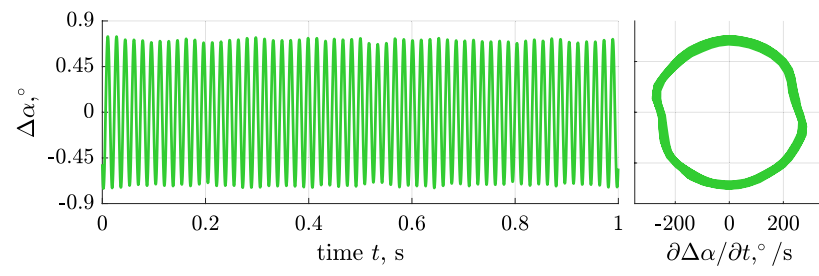

Fig. 7 Time series and phase space representation of a LCO in pitch of the laminar airfoil model

point. This leads to the increased values of the quasi-wall shear stress behind the transition line in Fig. 5a as well as to the large gradients in Fig. 5b. The interaction correlates with the end of the rapid drag increase at $\alpha \approx 0.2^{\circ}$, as marked in Fig. 6. While the shock begins to move downstream at $\alpha \approx 0.8^{\circ}$, the transition location follows.

In front of the transition line areas $\tau_{\mathrm{q}} \leq 0.02$ occur again, as soon as an shock occurs. This also indicates a possible separation bubble and corresponds to the observations at $\alpha \approx 1.2^{\circ}$ in Fig. $4 \mathrm{~b}$.
Figure 5 clearly shows the instability of the position of the boundary layer transition within the drag increase $-0.4^{\circ} \lesssim \alpha \lesssim 0.2^{\circ}$. Small changes of $\alpha$ lead to significant changes in $x_{\text {tr }}$, which can be interpreted as an indication of aeroelastic instabilities as they occur in the form of LCOs around $\alpha_{0} \approx 0^{\circ}$ for the laminar airfoil (Braune and Hebler 2018).

\subsection{Boundary layer transition during LCO}

An analysis of the temporal development of the quasi-wall shear stress is carried out, to investigate the unsteady boundary layer behavior while the laminar airfoil is performing a 1-DoF LCO in pitch. A LCO is considered for this purpose, which occurred at $\mathrm{Ma}=0.73, \operatorname{Re} \approx 2 \times 10^{6}$ and $\alpha \approx 0^{\circ}$. The behaviour of the aerodynamic force and pressure coefficients during the LCO was already discussed in Braune and Hebler (2018). A time section of the LCO is shown in Fig. 7. The LCO has an amplitude of $|\Delta \alpha| \approx 0.72^{\circ}$ and oscillates with a reduced frequency of $\omega^{*}=2 \pi f_{\alpha} c / u_{\infty} \approx 0.46$.
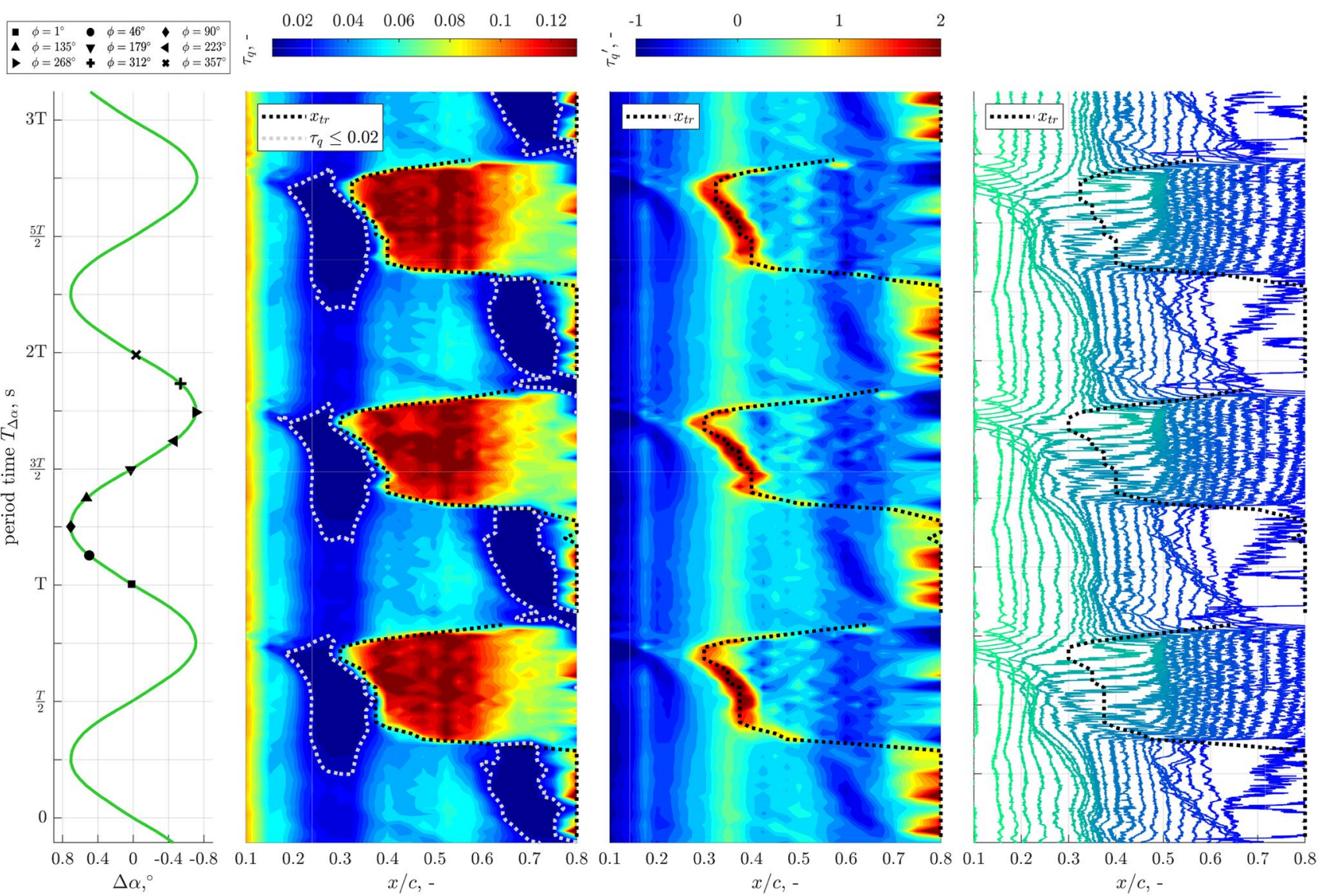

Fig. 8 Temporal and spatial development of the quasi-wall shear stress $\tau_{\mathrm{q}}(x / c, t)$, the spatial gradient $\tau_{\mathrm{q}}(x / c, t)^{\prime}$ and the voltage signals of the hot-film sensors of the laminar airfoil during a LCO. As before, regions $\tau_{\mathrm{q}} \leq 0.02$ and the detected transition line $x_{\mathrm{tr}}$ are depicted 

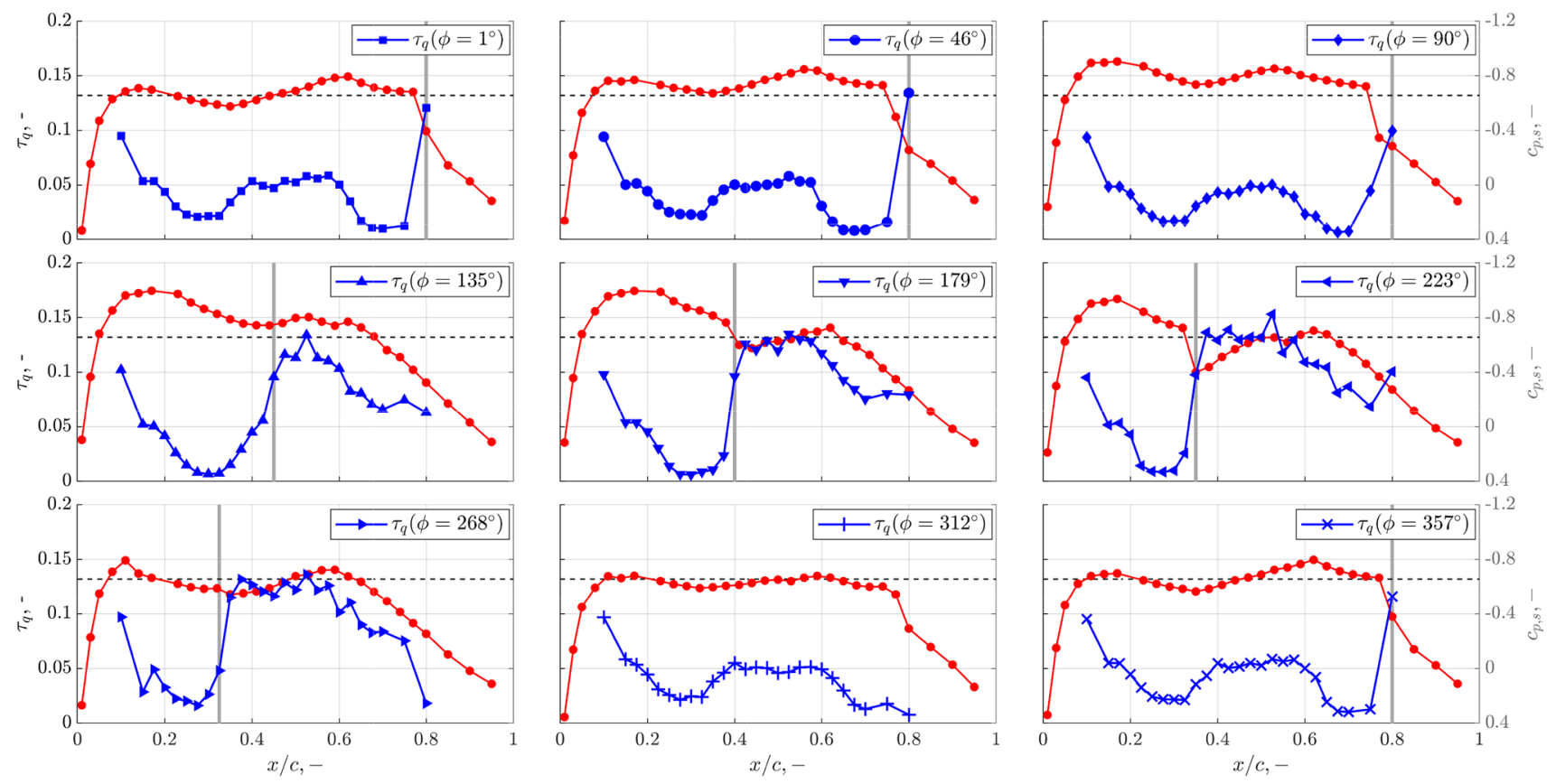

Fig.9 Quasi-wall shear stress $\tau_{\mathrm{q}}\left(x / c, t_{\phi_{i}}\right)$ (blue line) and pressure distribution $c_{\mathrm{p}, \mathrm{s}}$ (red line) for the phase angles marked in Fig. 8 of one oscillation period of the investigated LCO. The black dotted line

For the same time period discussed in Braune and Hebler (2018), the quasi-wall shear stress $\tau_{\mathrm{q}}(x / c, t)$, the gradient $\tau_{\mathrm{q}}{ }^{\prime}(x / c, t)$ and the real-time voltage signals of the hot-film sensors are shown for three oscillation periods in Fig. 8. As before, $\tau_{\mathrm{q}}(x / c, t)$ and $\tau_{\mathrm{q}}{ }^{\prime}(x / c, t)$ are represented by colorcoded contours. The position of the laminar-turbulent boundary layer transition $x_{\mathrm{tr}}(t)$ has been determined using the algorithm described in Sect. 3.4 and is shown as a black dotted line in Fig. 8. For convenience, only every fiftieth data point of the hot-film signals was used for this purpose, which offers sufficient time resolution due to the very high sampling rate of the MHFS array. The periodic motion of the model correlates with a periodic behavior of the transition location movement. In addition periodic formations of areas $\tau_{\mathrm{q}}<0.02$ appear, which give an indication of a periodic occurrence of laminar separation bubbles. These areas are also marked in Fig. 8.

For a more precise overview of the unsteady boundary layer behavior, nine phase angles $\phi$ with an increment of $\Delta \phi \approx 45^{\circ}$ were marked for one oscillation period in Fig. 8. For the corresponding times $t_{\phi_{i}}$ the respective trend $\tau_{\mathrm{q}}\left(x / c, t_{\phi_{i}}\right)$ and the pressure distribution $c_{\mathrm{p}, \mathrm{s}}\left(x / c, t_{\phi_{i}}\right)$ are shown individually in Fig. 9. The latter have already been discussed in Braune and Hebler (2018).

For the upward movement of the airfoil $\left(\phi=0^{\circ} \nearrow \phi=90^{\circ}\right)$ only a small change of the boundary layer and the pressure distribution occurs. For all three phase angles $\tau_{\mathrm{q}}$ starts to rise in the range of $0.3 \lesssim x / c \lesssim 0.4$, which marks the critical pressure coefficient $c_{\mathrm{p}}^{*}$, the gray line marks the position of the transition $x_{\text {tr }}$, estimated by the algorithm

correlates with a pressure increase and indicates a destabilization of the boundary layer. Initially $\tau_{\mathrm{q}}$ does not rise any further, but remains at an almost constant level, which is associated with an acceleration of the boundary layer due to a pressure drop. From $x / c \approx 0.6 \tau_{\mathrm{q}}$ drops and reaches very small values in the range of approx. $0.65 \lesssim x / c \lesssim 0.75$, which is an indication of a separation as confirmed by plateaus in the pressure distributions in front of the compression shock. The transition then occurs for all three phase angles in conjunction with the shock, which moves from nearly $x / c \approx 0.8$ for $\phi=1^{\circ}$ to $x / c \approx 0.75$ for $\phi=90^{\circ}$. The transition also moves upstream accordingly, but this is not detected by the spatially limited resolution of the MHFS array nor the transition detection algorithm. Thus a transition position of $x / c=0.8$ is estimated for all three phase angles, which is marked by grey vertical lines in Fig. 9.

At the beginning of the downstroke $\left(\phi=90^{\circ} \searrow \phi=270^{\circ}\right)$ of the airfoil, the transition moves very quickly upstream. For $\phi=135^{\circ}$ a pronounced supersonic area forms in the front area of the airfoil, which is attenuated by a pressure increase within the range $0.2 \lesssim x / c \lesssim 0.4$. This correlates with the boundary layer transition located at $x_{\text {tr }} \approx 0.45 c$, shown by an increase of $\tau_{\mathrm{q}}$ in this area. A compression shock does not occur at $\phi=135^{\circ}$. This changes in the next part of the downstroke motion, where the supersonic area closes with a compression shock, which induces the transition for $\phi=179^{\circ}$ and $\phi=223^{\circ}$. Shock and transition position correlate with 


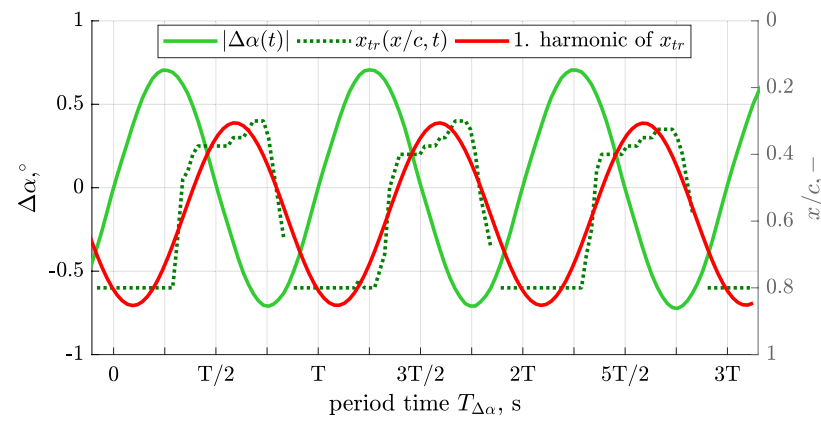

Fig. 10 Comparison of the airfoil motion with the transition movement represented by the first harmonic component of $x_{\mathrm{tr}}(x / c, t)$

$x_{\mathrm{tr}}\left(\phi=179^{\circ}\right) \approx 0.4 c$ and $x_{\mathrm{tr}}\left(\phi=223^{\circ}\right) \approx 0.35 c$, respectively. So both shock and transition move upstream. In addition, a comparison of $\phi=1^{\circ}$ and $\phi=179^{\circ}$ shows the influences of the unsteady flow due to the airfoil motion. The quasi-steady angle of attack is identical in both cases, but $c_{\mathrm{p}, \mathrm{s}}$ and $\tau_{\mathrm{q}}(x / c)$ differ significantly from each other. This is discussed in more detail in Sect. 4.3. For $\phi=179^{\circ}$ and $\phi=223^{\circ}, \tau_{\mathrm{q}}$ drops in front of the shock-induced transition to values close to zero, indicating a laminar separation bubble. This also applies to $\phi=135^{\circ}$ around $x / c \approx 0.3$. However, the pressure distributions show no significant plateaus. In front of the compression shocks, these are suggested, but no clear conclusions can be drawn. In the amplitude minimum of the LCO at $\phi=268^{\circ}$ the supersonic area has largely disappeared and no shock occurs. The transition results in an increase of $\tau_{\mathrm{q}}$ around $x_{\mathrm{tr}}=0.325 \mathrm{c}$ so that the laminar airfoil has the shortest laminar running length during a LCO period.

For $\phi=312^{\circ}$, during the renewed upstroke $\left(\phi=270^{\circ} \nearrow \phi=360^{\circ}\right), c_{\mathrm{p}}$ is nearly constant at $c_{\mathrm{p}}^{*}$. No transition occurs and $\tau_{\mathrm{q}}$ decreases continuously to the end of the sensor range. For $\phi=357^{\circ}$ a shock reoccurs around $x / c \approx 0.8$, which coincides with the transition. The occurring periodicity of the boundary layer behavior during the LCO leads to an approximately identical flow field as for $\phi=1^{\circ}$.

The methodology presented in Sect. 3.4 now allows to quantify the previously described unstable boundary layer behavior and to relate it to the airfoil motion, since an analysis of the acquired time series $x_{\mathrm{tr}}(t)$ can be performed. $x_{\mathrm{tr}}(x / c, t)$ (see Fig. 8) is shown in Fig. 10 together with the airfoil motion $\Delta \alpha$. With regard to a further analysis of the aeroelastic stability of the laminar airfoil, the phase lag between $\Delta \alpha$ and $x_{\mathrm{tr}}(x / c, t)$ is of interest. To define a phase difference, a linear relationship between airfoil and transition motion is assumed for simplification. A spectral decomposition of the transition motion has been performed and the first harmonic of $x_{\mathrm{tr}}(x / c, t)$, which has the same frequency as the airfoil motion, is filtered out (red line in Fig. 10). From this a transfer function can be calculated, with which a phase difference of $\Delta \varphi \approx-121^{\circ}$ between $\Delta \alpha$ and $x_{\mathrm{tr}}(x / c, t)$ can be estimated. So, the transition motion significantly lags behind the airfoil motion. Since this influences both the unsteady aerodynamic forces and the behavior of the compression shock, it is reasonable to assume that this delayed boundary layer response to the airfoil motion is an essential component of the observed aeroelastic instabilities.

\subsection{Unsteady shock-boundary layer interaction during LCO}

Besides the large phase lag between the motion of the boundary layer transition and the airfoil, a shock-boundary layer interaction occurs during the LCO. A type B shock motion according to Tijdeman and Seebass (1980) coincides with a periodic movement of the boundary layer transition, as shown in Sect. 4.2. To finally summarize this complex behavior, the results obtained in Sect. 4.2 are schematically illustrated for one LCO period in Fig. 11.

Two distinct areas occur where the boundary layer transition is shock-induced. During the upstroke movement ( $0 \leq \phi \leq \frac{\pi}{2}$ ), a shock occurs in the rear quarter of the laminar airfoil, which performs an inverse shock motion and moves minimally towards the leading edge. The boundary layer transition coincides with the shock and also moves minimally to the leading edge. The indicated laminar separation bubble in front of the shock follows this movement. With beginning downstroke, at the upper reversal point, the boundary layer transition jumps forward $\left(\phi=\frac{3}{4} \pi\right)$ and continuously moves upstream up to $x / c \approx 0.325$ for $\phi=\frac{3}{2} \pi$. The area around $\phi=\frac{3}{4} \pi$ and the reversal point $\phi=\frac{3}{2} \pi$ are shock-free. For $\pi \leq \stackrel{4}{\phi} \leq \frac{5}{4} \pi$ a shock region is formed at $x / c \approx 0.4$ moving upstream just like the transition. Again, the results provide indications of a separation bubble before the shock. Behind the lower reversal point for $\phi=\frac{7}{4} \pi$ no boundary layer transition can be detected within the hot-film sensor range. The transition has shifted by at least half the chord to the trailing edge. Only at the end of a full period ( $\phi=2 \pi$ or $\phi=0)$ a transition can be localized again around $x / c=0.8$, which occurs in connection with a shock.

Thus, during a LCO period there is a sudden movement of the boundary layer transition, especially in the upper and lower reversal point of the airfoil motion. At the upstroke and downstroke, a shock-induced transition occurs after each zero crossing of $\Delta \alpha$. Both effects correlate with a strong change in the flow velocities induced by the motion or a related change in the local angle of attack. As a result of the pitch motion of the laminar airfoil about the axis of rotation at $c / 4$, an upstroke motion can 


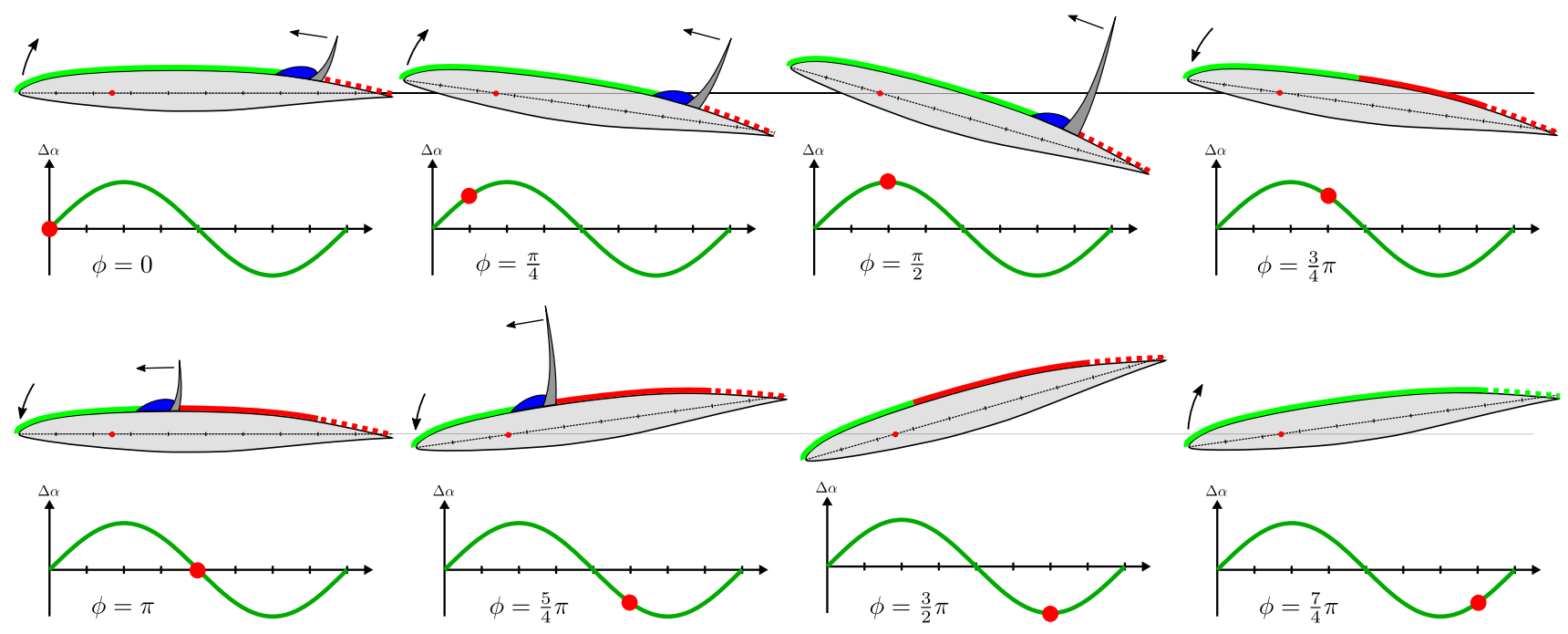

Fig. 11 Schematic visualization of laminar-turbulent boundary layer transition and the shock-boundary layer interaction for one period of the analyzed LCO. Laminar areas of the boundary layer are shown in green, whereas turbulent areas are shown in red. Laminar separation bubbles, as far as they can be determined, are visualized schemati-

be interpreted as a reduction in the local angle of attack in front of $c / 4$ and as an increase behind $c / 4$. This local increase leads to an acceleration of the flow and consequently to a stabilization of the boundary layer. This results in a long laminar running length, which is present during the upstroke motion. This process reverses accordingly as soon as the model executes a downstroke motion and consequently leads to an earlier boundary layer transition upstream. In addition to influencing the boundary layer transition, the induced velocities also influence the pressure distribution and thus the shock position, which in turn interacts with the boundary layer. These aspects also explain the large phase shift between model movement and boundary layer transition. Therefore, the conclusion is obvious that the observed effects depend not only on the stationary flow field but also on the LCO amplitude and especially on the LCO frequency, which is decisive for the induced velocities. With regard to the question of the aeroelastic stability, it must be clarified to what extent the observed transition motion in connection with the shock-boundary layer interaction is induced by the airfoil motion, i.e., is to be understood as a forced-excited fluid oscillation, or whether a self-excited oscillation has decisively induced the motion of the airfoil. An analysis of these relationships is the subject of further investigations. cally in blue and shocks in grey. Behind $x / c=0.8$ no boundary layer information is available anymore and the prevailing boundary layer states are extrapolated to the trailing edge. A possible flow separation at this point is not considered

\section{Concluding remarks}

This paper presented an investigation of the unsteady boundary layer transition and shock-boundary layer interaction on a CAST 10-2 supercritical laminar airfoil in transonic unsteady flow. CTA measurements using an MHFS array were performed while the model experienced 1-DoF LCOs in pitch. The hot-film signals were evaluated on the basis of the physically motivated quasi-wall shear stress, whereby in particular the laminar-turbulent boundary layer transition was resolved. A three-stage algorithm was developed, on the basis of which a detection of the transition is also possible during unsteady measurements and occurring shock-boundary layer interaction. For the first time, this enabled a direct relationship between the airfoil motion during a LCO and the motion of the boundary layer transition for transonic flow conditions to be derived and quantified.

In the steady case, the airfoil model shows a clear shift of the transition position for $\mathrm{Ma}=0.73$ as a function of the angle of attack. A characteristic plateau in the drag polar for the laminar airfoil is also detectable. At the edge of the plateau, a shock-boundary layer interaction occurs. Transition and shock position coincide in these cases. Furthermore, the results give indications of a laminar separation bubble that forms upstream of the shock. The unsteady boundary layer behavior and the position of the transition during a LCO show a clear deviation to the steady case. A sudden movement of the boundary layer transition occurs in the upper and lower reversal points of the LCO, whereas a shock-induced transition in combination with an indicated 
laminar separation bubble occurred in the last section of the upstroke and downstroke. This is directly related to the locally induced velocities as a result of the unsteady flow during the airfoil motion, which lead to a delay and thus to a phase lag between the airfoil motion and the movement of the laminar-turbulent boundary layer transition. This in turn affects the aerodynamic forces and thus the aeroelastic stability of the laminar airfoil. The more detailed interaction will be investigated in further studies.

Some extensions and improvements can still be made regarding the evaluation of the hot-film signals. The theoretical principles on which the derivation of the quasi-wall shear stress is based are subject to some assumptions and simplifications. Especially in connection with the transonic flow local compressibility and temperature effects occur, which influence the heat transfer and thus the sensor signal. This is not taken into account here. It is obvious, however, that these effects are negligible with regard to a purely qualitative interpretation of the quasi-wall shear stress, since the trend and not the overall values are evaluated. Concerning a temperature correction of the individual sensors, there are other temperature correction methods than those used in this work, which may be more accurate under the aspects mentioned above. The requirement of the temperature correction applied here was primarily an adjustment of the signals of different measuring points due to the warming of the wind tunnel.

The detected transition position is currently linked to a hot-film sensor position, so that smaller transition movements below the sensor spacing are not resolved. A suitable interpolation of $\tau_{\mathrm{q}}(x)$ would result in a smoother curve with more interpolation points. An interpolation with a higherorder polynomial would be conceivable, whereby all further steps for transition detection could be performed continuously and discretization would no longer be necessary. The detection of the strongest rise of $\tau_{\mathrm{q}}(x)$ and thus $x_{\mathrm{tr}}$ would no longer be based on the individual sensor position. This would lead to a spatially higher resolution of the detected transition position. An extension of the algorithm would also be conceivable to capture not only a transition position, but also the spatial extent of the transition area. This is currently not possible in an automated way due to a too-strong scattering of the discrete measured values or the curve of $\tau_{\mathrm{q}}(x)$. An improvement in the down-sampling of unsteady measurement series would also be conceivable. So far, every fiftieth measuring point of the hot-film sensors is used to determine the transition position. This down-sampling could also be done using a moving average, including the data points before and after every fiftieth data point. This would make better use of the full sampling rate of the hot-films and the associated high temporal resolution. This would probably result in smoother curves for $\tau_{\mathrm{q}}\left(x, t_{i}\right)$ already in the first step of the transition algorithm, which favors subsequent steps or an additional interpolation.

Nevertheless, the presented work successfully shows that on the basis of the evaluation methodology of the hot-films a largely automated detection of the unsteady boundary layer transition is possible, even under transonic flow and associated shock-boundary layer interaction. Ongoing work is now focusing on establishing a connection between the delayed boundary layer response in conjunction with the occurring shock-boundary layer interaction and the energy input of the flow into the motion of the model. The aim is to identify the flow processes and conditions leading to the occurrence of LCOs and the associated aeroelastic instability of the laminar airfoil more accurately.

Acknowledgements Open Access funding provided by Projekt DEAL.

Open Access This article is licensed under a Creative Commons Attribution 4.0 International License, which permits use, sharing, adaptation, distribution and reproduction in any medium or format, as long as you give appropriate credit to the original author(s) and the source, provide a link to the Creative Commons licence, and indicate if changes were made. The images or other third party material in this article are included in the article's Creative Commons licence, unless indicated otherwise in a credit line to the material. If material is not included in the article's Creative Commons licence and your intended use is not permitted by statutory regulation or exceeds the permitted use, you will need to obtain permission directly from the copyright holder. To view a copy of this licence, visit http://creativecommons.org/licenses/by/4.0/.

\section{References}

Bellhouse BJ, Schultz DL (1966) Determination of mean and dynamic skin friction, separation and transition in low-speed flow with a thin-film heated element. J Fluid Mech 24(2):379400. https://doi. org/10.1017/S0022112066000715

Braune M, Hebler A (2020) Sensitivity of single degree of freedom limit cycle flutter of a laminar airfoil and resulting uncertainties of the transonic dip. In: Dillmann A, Heller G, Krämer E, Wagner $\mathrm{C}$, Tropea C, Jakirlic S (eds) New results in numerical and experimental fluid mechanics XII, notes on numerical fluid mechanics and multidisciplinary design, vol 142. Springer, Berlin, pp 481-490. https://doi.org/10.1007/978-3-030-25253-3

Braune M, Hebler A (2018) Experimental investigation of transonic flow effects on a laminar airfoil leading to limit cycle oscillations. In: (2018) Applied aerodynamics conference, AIAA AVIATION Forum, 25-29 June 2018. Atlanta, Georgia. https://doi. org/10.2514/6.2018-3641

Dietz G, Schewe G, Mai H (2006) Amplification and amplitude limitation of heave/pitch limit-cycle oscillations close to the transonic dip. J Fluids Struct 22:505527. https://doi.org/10.1016/j.jfluidstru cts.2006.01.004

Fehrs M (2013) Influence of transitional flows at transonic Mach numbers on the flutter speed of a laminar airfoil. In: International forum on aeroelasticity and structural dynamics (IFASD), 24-26 June 2013, Bristol, United Kingdom

Fehrs M, van Rooij ACLM, Nitzsche J (2015) Influence of boundary layer transition on the flutter behavior of a supercritical airfoil. CEAS Aeronaut J 6(2):291303 
Goerttler A, Gardner A, Richter K (2017) Unsteady boundary layer transition detection by automated analysis of hot film data. In: Dillmann A, Heller G, Krämer E, Wagner C, Bansmer S, Radespiel R, Semaan R (eds) New results in numerical and experimental fluid mechanics XI, notes on numerical fluid mechanics and multidisciplinary design, vol 136. Springer, Berlin, pp 387-395. https://doi.org/10.1007/978-3-319-64519-3_35

Hebler A (2017) Experimental assessment of the flutter stability of a laminar airfoil in transonic flow. In: International forum on aeroelasticity and structural dynamics (IFASD), 25-28 June 2017, Como, Italy

Hebler A, Schojda L, Mai H (2013) Experimental investigation of the aeroelastic behaviour of a laminar airfoil in transonic flow. In: International forum on aeroelasticity and structural dynamics (IFASD), 24-26 June 2013, Bristol, United Kingdom

Hodson HP (1985) Boundary-layer transition and separation near the leading edge of a high-speed turbine blade. J Eng Gas Turbines Power 107(1):127134. https://doi.org/10.1115/1.3239672

Hodson HP, Huntsman I, Steele AB (1994) An investigation of boundary layer development in a multistage LP turbine. J Turbomach 116(3):375-383. https://doi.org/10.1115/1.2929424

Hultmark M, Smits AJ (2010) Temperature corrections for constant temperature and constant current hot-wire anemometers. Meas Sci Technol 21:10. https://doi.org/10.1088/0957-0233/21/10/105404

King LV, Barnes HT (1914) On the convection of heat from small cylinders in a stream of fluid: Determination of the convection constants of small platinum wires, with applications to hot-wire anemometry. Proc R Soc Lond Ser A Contain Pap Math Phys Char. https://doi.org/10.1098/rspa.1914.0089

Lee T, Basu S (1998) Measurement of unsteady boundary layer developed on an oscillating airfoil using multiple hot-film sensors. Exp Fluids 25(2):108117. https://doi.org/10.1007/s003480050214

Lee D, Kawai S, Nonomura T, Anyoji M, Aono H, Oyama A, Asai K, Fujii K (2015) Mechanisms of surface pressure distribution within a laminar separation bubble at different Reynolds numbers. Phys Fluids 27:2. https://doi.org/10.1063/1.4913500

Leuckert J, Erdmann R, Nitsche W, Rosemann H (2011) On transition detection at high subsonic freestream mach numbers using thermoresistive surface sensors. In: 49th AIAA aerospace sciences meeting including the new horizons forum and aerospace exposition Orlando, Florida. https://doi.org/10.2514/6.2011-879

Liepmann HW, Skinner GT (1954) Shearing-stress measurements by use of a heated element. Technical Note 3268, National Advisory Committee for Aeronautics
Mai H, Hebler A (2011) Aeroelasticity of a laminar wing. In: International forum on aeroelasticity and structural dynamics (IFASD), 26-30 June 2011, Paris, France

Richter K, Koch S, Gardner A, Mai H, Klein A, Rohardt CH (2014) Experimental investigation of unsteady transition on a pitching rotor blade airfoil. J Am Helicopt Soc 59:1. https://doi. org/10.4050/JAHS.59.012001

Richter K, Koch S, Gardner A (2013) Influence of oscillation amplitude and Mach number on the unsteady transition on a pitching rotor blade airfoil. In: AHS 69th annual forum, Phoenix, Arizona, May 21-23

Richter K, Koch S, Goerttler A, Lütke B, Wolf CC, Benkel A (2015) Unsteady boundary layer transition on the DSA-9a rotor blade airfoil. In: 41st European rotorcraft forum, Munich, Germany, 01. -04. September

Richter K, Wolf CC, Gardner A, Merz CB (2016) Detection of unsteady boundary layer transition using three experimental methods. In: 54th AIAA aerospace sciences meeting, 4-8 January, San Diego, California, USA. https://doi.org/10.2514/6.2016-1072

Roberts WB (1980) Calculation of laminar separation bubbles and their effect on airfoil performance. AIAA J 18(1):2531. https:// doi.org/10.2514/3.50726

Tichy L, Mai H, Fehrs M, Nitzsche J, Hebler A (2017) Risk analysis for flutter of laminar wings. In: International forum on aeroelasticity and structural dynamics (IFASD), 25-28 June 2017, Como, Italy

Tijdeman H, Seebass R (1980) Transonic flow past oscillating airfoils. Annu Rev Fluid Mech 12:181222. https://doi.org/10.1146/annur ev.fl.12.010180.001145

van Rooij ACLM, Wegner W (2014) Numerical investigation of the flutter behavior of a laminar supercritical airfoil. In: Dillmann A, Heller G, Krämer E, Kreplin HP, Nitsche W, Rist U (eds) New results in numerical and experimental fluid mechanics IX, notes on numerical fluid mechanics and multidisciplinary design, vol 124. Springer, Berlin, pp 33-41. https://doi.org/10.1007/978-3319-03158-3

Publisher's Note Springer Nature remains neutral with regard to jurisdictional claims in published maps and institutional affiliations. 